\title{
PROPOSTA DE CRIAÇÃO DE UMA ESTAÇÃO ECOLÓGICA NO CAMPUS DE UMA UNIVERSIDADE FEDERAL NO ESTADO DO CEARÁ
}

\section{PROPOSAL FOR THE CREATION OF AN ECOLOGICAL STATION IN THE CAMPUS OF A FEDERAL UNIVERSITY IN THE STATE OF CEARÁ}

\author{
Lisandra Rebpuças Barros ${ }^{1}$; Paulo Henrique Gomes de Oliveira Sousa ${ }^{2}$; Iury Alberto Mota de \\ Lima $^{3}$; Jose Abel Aguiar Silva Paz ${ }^{4}$; Luís Gustavo Chaves da Silva ${ }^{5}$
}

DOI: $\underline{\text { https://doi.org/10.31692/978-65-991061-7-0.270-281 }}$

\section{RESUMO}

Em 18 de julho de 2000 foi sancionada a Lei n. ${ }^{\circ} 9.985$ que instituiu o Sistema Nacional de Unidades de Conservação da Natureza (SNUC). Esta Lei determina em seu texto a necessidade, da implantação e regularização de Unidades de Conservação (UC) por todo o perímetro do território nacional, estabelecendo seu zoneamento ambiental e normas necessárias para gerir o uso de sua área e o manejo de seus recursos naturais. As Unidades de Conservação representam uma estratégia importante para preservação da natureza, pois são refugos de fauna e flora, bem como auxiliam na manutenção de fatores ambientais essenciais a ecossistemas, como mananciais, cursos d'agua e na microbiota do solo, além de tal preservação ser imprescindível na manutenção do equilibrio ecológico como um todo. A área em estudo trata-se de um bioma caracterizado como Mata Seca, vegetação extremamente rara em território cearense, esse bioma refere-se a um ecossistema que merece atenção em função da sua fragilidade ambiental, onde as principais ameaças observadas são a exploração irregular de madeira, produção de carvão vegetal, bem como, a pressão imobiliária, por residência e loteamentos próximos a universidade, além de tal salvaguarda evitar queimadas, tão contumeiras na região em períodos secos, favorecendo assim a sustentabilidade do local. Este estudo tem como objetivo propor a criação da Unidade de Conservação de Proteção Integral - Estação Ecológica Auroras (ESECA) na área inserida no campus das Auroras pertecente a Universidade da Integração Internacional da Lusofonia Afro-Brasileira (UNILAB) - Campus Auroras, localizado entre as cidades de Redenção e Aracape, no Estado do Ceará.

Palavras-Chave: agroecologia, recuperação de áreas, sustentabilidade

\section{ABSTRACT}

On July 18, 2000, Law No. 9.985, which established the National System of Nature Conservation Units (SNUC), was sanctioned. This Law determines in its text the need for the implementation and regularization of Conservation Units (UC) throughout the national territory, establishing its environmental zoning and standards necessary to manage the use of its area and the management of its natural resources. Conservation Units represent an important strategy for the preservation of nature, as they are scraps of fauna and flora, as well as assist in the maintenance of environmental factors essential to ecosystems, such as water sources, watercourses and soil microbiota, in addition to such preservation be essential in

\footnotetext{
1 Agronomia, Universidade da Integração Internacional da Lusofonia Afro-Brasileira, $\frac{\text { lisandrareboucasbarros@gmail.com }}{2 \text { Professor Visitante, Universidade da Integração Internacional da Lusofonia Afro-Brasileira, }}$ sousaph@unilab.edu.br

${ }_{3}^{3}$ Agronomia, Universidade da Integração Internacional da Lusofonia Afro-Brasileira, iury.mota@bol.com.br ${ }^{4}$ Agronomia, Universidade da Integração Internacional da Lusofonia Afro-Brasileira, abelpaz06@gmail.com 5 Professor Efetivo, Universidade da Integração Internacional da Lusofonia Afro-Brasileira, chaveslg@unilab.edu.br
} 
maintaining the ecological balance as a whole. The studied area is a biome characterized as Mata Seca, an extremely rare vegetation in the territory of Ceará, this biome refers to an ecosystem that deserves attention due to its environmental fragility, where the main threats observed are the irregular exploitation of wood, charcoal production, as well as, real estate pressure, by residence and allotments near the university, in addition to such a safeguard to avoid burnings, so contumeiras in the region in dry periods, thus favoring the sustainability of the place. The aim of this study is to propose the creation of the Comprehensive Protection Conservation Unit - Auroras Ecological Station (ESECA) in the area of the Auroras campus, located at the University of the International Integration of Afro-Brazilian Lusophony (UNILAB) - Campus Auroras, located between cities of Redenção and Aracape, in the State of Ceará.

Keywords: agroecology, restoration of areas, sustainability

\section{INTRODUÇÃO}

As Unidades de Conservação se apresentam como o meio ecológico e economicamente mais viável para a manutenção de ecossistemas propensos ao desmatamento e intenso uso humano, a conversão de áreas naturais para agricultura e crescimento urbano estão entre as principais causas de destruição e fragmentação de ecossistemas (UNDP, UNEP, WB, WRI 2000). Áreas urbanas já ocupam 471 milhões de hectares (em torno de 4\% da superfície terrestre do planeta), o que torna necessário pensar a conservação biológica também em áreas dentro das cidades (UNDP, UNEP, WB, WRI 2000; MCKINNEY 2002, 2006), além disso, dados do Ministério do Meio Ambiente (BRASIL, 2016) indicam que a taxa de desmatamento no país totalizou cerca de $7.989 \mathrm{~km}^{2}$, o que representa um crescimento de $29 \%$ na comparação ao ano anterior, tornando clara a necessidade de intervenções pontuais a fim de gerar uma maior segurança ambiental e jurídica ao perímetro que a referida Unidade.

Segundo SILVA (2014) as unidades de conservação da natureza surgem no contexto atual, como um instrumento importante no auxílio do controle e equilíbrio ambiental, estabelecendo limites ao direito de propriedade, tanto na esfera particular como no âmbito estatal, evitando assim crises em toda uma biota, devido à escassez de recursos fundamentais à manutenção de um bioma.

Partindo de uma breve reflexão sobre a criação de unidades de conservação que compreende, dentre outros aspectos, a proteção ao meio ambiente, estudos ecológicos sobre a flora e a fauna, a situação fundiária, a ocupação de seres humanos e as atividades econômicas envolvidas na área.

De acordo com MEDA (2014) no caso da criação das unidades de conservação temse como necessário assegurar a conservação de extensões significativas dos ambientes naturais, isto é, a proteção do meio ambiente cujo objetivo se reflete na proteção de áreas de importância biológica e cultural ou de beleza cênica ou ainda assegurar o uso sustentável dos 
recursos naturais para as populações que ali residem.

A cidade de Redenção, com uma área aproximada de 225.626 km², está situada na cota $88 \mathrm{~m}$ acima do nível com centro geométrico nas coordenadas de latitude $4^{\circ} 13^{\prime} 33^{\prime \prime} \mathrm{e}$ longitude 38 43' 50", em uma formação geológica denominada Maciço de Baturité, que apresenta rochas ígneas, metamórficas e sedimentares e ponto culminante a (IPECE, 2016). A Mata Seca é a fitofisionomia básica (transição entre biomas Mata Atlântica / Caatinga) predominante na área em estudo, com tipo de vegetação de Caatinga Arbustiva Densa a Floresta Subcaducifólia Tropical Pluvial (IPECE, 2006). O relevo se apresenta acidentado, com declividades superiores a 30\%. Recebendo classificação oficial de Maciço Residual, de origem cristalina, podendo ainda apresentar características de Depressão Sertaneja. Os solos variam entre Planossolo e Podzólico. O clima é classificado como tropical com estação seca de inverno (AW), segundo classificação climática de Koppen, sendo considerado ainda variável entre Tropical Quente Úmido, Tropical Quente Sub-úmido e Tropical Quente Semiárido Brando. A pluviosidade média é de 1.062,00 $\mathrm{mm}$; temperatura média variando entre $26^{\circ}$ a $28^{\circ} \mathrm{C}$ e quadra chuvosa de janeiro a abril (IPECE). A região possui 13 cidades e entre elas apenas uma Unidade de Conservação Estadual, sendo esta de uso sustentável, de jurisdição da Secretaria de Meio Ambiente do Estado do Ceará (APA do Maciço de Baturité), mais outras 3 Reservas Particulares de Patrimônio Natural (RPPNs), nos municípios de Pacoti e Mulungu e ainda o corredor ecológico do rio Pacoti, que se inicia em Redenção e segue ao litoral. Nenhum município pertencente ao Maciço apresenta Unidade de Conservação (UC) de Proteção Integral, fazendo clara a necessidade da criação e implantação da UC proposta.

O estudo preliminar para criação de uma UC na região de Redenção/Acarape do tipo Estação Ecológica (ESEC), considera a significância ambiental do perímetro proposto, de mata seca, sendo esta, transição entre mata úmida (cotas superiores a $400 \mathrm{~m}$ do nível do mar) e caatinga (contas inferiores a $100 \mathrm{~m}$ do nível do mar). A área em discussão está inserida, nas dependências da Universidade da Integração Internacional da Lusofonia Afro-Brasileira (UNILAB), entre as contas aproximadas de $90 \mathrm{~m}$ à $400 \mathrm{~m}$ do nível do mar, sendo a primeira proposta de estudo de viabilidade para criação da Estação Ecológica Auroras (ESECA), com a função de proteção de nascentes e cursos d’água de vital importância para a manutenção da fauna e flora da região, proteção do solo, objeto de estudo para os docentes e discente da UNILAB e outras instituições interessadas na fauna e flora local, ferramenta de educação ambiental voltada aos cidadãos da região, bem como, outros serviços ecossistêmicos.

O objetivo deste trabalho é apresentar uma proposta de área para da criação da Unidade de Conservação de Proteção Integral - Estação Ecológica Auroras (ESECA) na 
área inserida no campus Auroras da UNILAB (CE). Está UC terá usos voltados para pesquisas realizadas na universidade e escolas do Maciço de Baturité, além de subsidiar a educação ambiental na região.

\section{FUNDAMENTAÇÃO TEÓRICA}

Visando a proteção da fauna e da flora, levando-os em consideração como bens ambientais, o sistema de proteção ambiental no Brasil, através da Política Nacional do Meio Ambiente - PNMA (Lei n. ${ }^{\circ}$ 6.938/81), entende que os entes públicos, nos diversos níveis de governança, instituam os "espaços territoriais especialmente protegidos". O grau de sua importância está em que a lei entende por esses "espaços" como um dos instrumentos para a garantia da compatibilização entre o desenvolvimento econômico-social e a preservação da qualidade do meio ambiente e seu equilíbrio ecológico, a teor do disposto no art. 9. ${ }^{\circ}$, inciso VI:

\footnotetext{
Art. $9^{\circ}$ - São instrumentos da Política Nacional do Meio Ambiente:

$[\ldots]$

VI - a criação de espaços territoriais especialmente protegidos pelo Poder Público federal, estadual e municipal, tais como áreas de proteção ambiental, de relevante interesse ecológico e reservas extrativistas.
}

Conforme LEITE \& SANTOS (2015) no Brasil, estes espaços territoriais especiais são divididos em duas grandes categorias: a) lato sensu: Área de Reserva Legal - ARL (definida no Código Florestal); Área de Preservação Permanente - APP (definida no Código Florestal); Biomas considerados patrimônio nacional (previstos na Constituição Federal, art. 225, § 4. ${ }^{\circ}$ ); Reserva Exclusiva (prevista na Lei de Gestão das Florestas Públicas); Servidão Ambiental (prevista no Código Florestal); b) stricto sensu: Unidade de Conservação - UC (prevista na Lei n. ${ }^{\circ}$ 9.985/2000, que institui o Sistema Nacional de Unidades de Conservação da Natureza).

O Sistema Nacional de Unidades de Conservação - SNUC está previsto no artigo $3^{\circ}$ da Lei 9985/2000 como "conjunto de unidades de conservação federais, estaduais e municipais". As referidas unidades de conservação, inseridas que estão no SNUC, são entendidas como espaços territoriais públicos ou privados, que por ato do Poder Público, são destinadas ao estudo e à preservação, levando em consideração que são áreas protegidas, definidas geograficamente, para alcançarem objetivos específicos de conservação, conforme artigo $2^{\circ}$, inciso I da lei em comento.

As unidades de conservação integrantes do SNUC dividem-se em dois grupos com características específicas conforme disposto no artigo $7^{\circ}$ da Lei 9.985/2000, são elas: as 
Unidades de Proteção Integral composta por: Estação Ecológica; Reserva Biológica; Parque Nacional; Monumento Natural e Refúgio de Vida Silvestre, por outro lado as Unidades de Uso Sustentável composta por: Áreas de Proteção Ambiental; Área de Relevante Interesse Ecológico; Floresta Nacional; Reserva Extrativista; Reserva de Fauna; Reserva de Desenvolvimento Sustentável e Reserva Particular do Patrimônio Natural, compilando, assim, 12 categorias de unidades de conservação.

A Lei Complementar 140/2011 reconhece que são competentes para criar Unidades de Conservação a União, art. $7^{\circ}, \mathrm{X}$; os Estados, art. $8^{\circ}, \mathrm{X}$, e os Municípios, art. $9^{\circ}, \mathrm{X}$; cada um no âmbito de suas competências.

Conforme, ANTUNES (2005) as Unidades de Proteção Integral têm por objetivo básico a preservação da natureza, admitindo o uso indireto de seus recursos naturais, excetuando os casos previstos na lei do SNUC, ao passo que as Unidades de Uso Sustentável destinam-se à compatibilização entre a conservação da natureza com o uso sustentável de parcela dos seus recursos naturais, portanto, cada modelo de unidade de conservação corresponde a um determinado padrão de limitação de atividades econômicas, sociais, turísticas, dentre outros.

Tratando-se especificamente da Estação Ecológica (ESEC), segundo o Ministério do Meio Ambiente (2000) esta é uma área terrestre ou marinha instituída pelo poder público, que tem como objetivo a preservação da natureza e a realização de pesquisas científicas. É de posse e domínio públicos, sendo que as áreas particulares incluídas em seus limites devem ser desapropriadas. Nessa unidade, é proibida a visitação pública, exceto quando com objetivo educacional, de acordo com o que dispuser o Plano de Manejo da unidade ou regulamento específico, e a pesquisa científica depende de autorização prévia do órgão responsável pela administração da unidade e está sujeita às condições e restrições por este estabelecidas, devido ao exposto a escolha da criação no domínio Estação Ecológica se faz clara, priorizando a pesquisa científica a ser desenvolvida na área e por sua regulamentação ser, como cita a proposta, da Universidade facilitando assim, o gerenciamento desta.

\section{METODOLOGIA}

A proposta de criação de UC leva como premissa básica a proteção do meio ambiente este se reflete diretamente na proteção de áreas de importância biológica e cultural ou de beleza cênica.

O Ministério do Meio Ambiente aponta que a criação de UC pelo Poder Público deve ser precedida de realização de estudos técnicos para identificar a localização, a dimensão e os 
limites mais adequados para a unidade. $\mathrm{O}$ estudo técnico supramencionado iniciou-se utilizando a base cartográfica gerada pela UNILAB a partir do levantamento topográfico detalhado do Campus das Auroras.

O serviço foi realizado por empresa especializada em agrimensura e topografia, contratada em 2015. Todo levantamento foi executado com aparelho GNSS Geodésico pela técnica Real-Time Kinematic (RTK) seguindo a NBR13133, processada para o formato de planta topográfica em DXF. Esses dados foram gentilmente fornecidos pela Pró-Reitoria de Planejamento (PROPLAN) da Universidade.

O programa Google Earth Pro foi utilizado para visualizar os dados coletados. O uso de ferramentas de desenho e medição do Google Earth Pro empregadas para simulações e observações dos critérios adotados, utilizando a importação de dados em formato DXF para o formato KML. Foram traçadas linhas de caminhamento e a ferramenta "Mostrar perfil de elevação", para análise do perfil do terreno nos sentidos Noroeste-Sudeste e NordesteSudoeste (Figura 3).

Os dados foram analisados em ambiente de Sistema de Informações Geográficas ARCGIS e delimitadas as feições das áreas em uso e construídas, mas não inauguradas, pela universidade (bloco didático, residências estudantis, restaurante universitário, unidade de produção de mudas de espécies nativas e estação de tratamento de esgoto e os acessos), áreas edificáveis que iram compor o plano de expansão da universidade, considerando com critério declividades médias inferiores a 30\% e o restante das áreas ficaram destinadas a ESECA.

\section{RESULTADOS E DISCUSSÃO}

Foi possível avaliar a área definida para implantação da ESECA através do Google Earth Pro para identificação das formas de relevo e uso do ArcGIS para se trabalhar com os dados fornecidos pela PROPLAN em ambiente de SIG (Figura 4). Foram observadas as condições de declividades pontuais com o uso do Google Earth Pro, sendo possível comparar com a base cartográfica da UNILAB e confirma as condições acidentadas do terreno de forma geral, onde não se justifica economicamente e ambientalmente qualquer indicação de uso para construções de expansão nas declividades acima da 30\%, que coincide com a cota 100 metro do nível do mar na maior parte das áreas observadas.

Declividades a partir de $45^{\circ}$ são consideradas como Áreas de Preservação Permanente (APP) segundo o artigo $4^{\circ}$, inciso V, da Lei n. 12.651/2012 (Código Florestal), sendo outro forte indício de uso especial para a área e que a experiência de construções em pontos mais elevadas nos limites da Universidade, se mostraram de difícil execução técnica e 
grande custo financeiro (uso de dinamização e remoção de grandes blocos rochosos), fortalecem a proposta apresentada de criação de UC.

Não há trabalhos detalhados quanto a fitossociologia das espécies para área proposta, mas em análises preliminares foram constatadas diversas espécies nativas importantes, Catingueira (Caesalpinia pyramidalis), Aroeira-do-sertão (Myracrodruon urundeuva), Sabiá (Mimosa caesalpineaefolia), Ipê Roxo (Androanthus impepetiginosus), Feijão-bravo (Capparis flexuosas), Mororó (Bauhinia macrostachya) Pau-Branco-do-Sertão (Auxemma oncocalyx), entre outras. A definição da área e realização de monitoramentos e de estudos de caráter fitossociológicos Lemos e Meguro (2015) permitirão conhecer em detalhes as espécies da região.No que concerne à fauna, foi verificado a ocorrência de macacos, serpentes, e várias espécies de pássaros. A criação de uma UC pode promover a proteção e a abundância desses animais (Oliveira et al., 2016).

Esta área é constantemente ameaçada pela retirada ilegal de madeira, caça/captura de fauna, circulação de pessoas, circulação de animais domésticos (criações), crescimento urbano (o perímetro da universidade não é delimitado por cercas), ocorrência de espécies exóticas invasoras e principalmente incêndios florestais (fabricação de carvão e incêndios vindos dos confinantes). Com a criação de uma UC Federal, seria possível, direcionar recursos e logística de apoio dos órgãos de fiscalização federal de forma mais otimizada e eficiente, como o programa PREVFOGO e fiscalizações ostensivas do IBAMA.

Neste contexto, espera-se apoio do ICMBIO, não apenas na criação, mas também nas propostas de plano de manejo e suporte financeiro quando possível. Outra condição favorável, é a relação formal entre a Secretaria do Meio Ambiente do Estado do Ceará (SEMA) com base em acordo de cooperação técnica assinada em 2016 com a UNILAB, onde a experiência com a APA do Maciço de Baturité será de grande valor e a interação técnica entre agências governamentais concorrendo para o sucesso da UC em seus propósitos. Reforça-se ainda nesta temática de cooperação técnica, acordos vigentes com a Superintendência de Meio Ambiente do Estado do Ceará SEMACE e as Secretarias Municipais de Agricultura e Meio Ambiente dos municípios de Redenção e Acarape, operando de forma ativa em ações do Cadastro Ambiental Rural (CAR), Recuperação de Áreas Degradadas (RAD), gerenciamento de resíduos sólidos e reuso de águas. É sabido que a vegetação sofre com os efeitos negativos do uso e ocupação do solo ao longo do tempo (BEUCHLE et al., 2015; MARINHO et al., 2018),

Considerando a criação de uma UC de Proteção Integral, conforme os preceitos do SNUC (Lei 9.985, de 18/07/2000), uma Estação Ecológica tem como objetivo a preservação 
da natureza e a realização de pesquisas científicas. É de posse e domínio públicos, sendo as áreas particulares incluídas em seus limites desapropriadas. A visitação pública é proibida, exceto para objetivo educacional, de acordo com o Plano de Manejo da UC ou regulamento específico, e a pesquisa científica depende de autorização prévia do órgão responsável pela administração da unidade e sujeita às condições e restrições estabelecidas. Nas ESEC são permitidas alterações dos ecossistemas no caso de: a) medidas que visem à restauração de ecossistemas modificados; b) manejo de espécies com o fim de preservar a diversidade biológica; c) coleta de componentes dos ecossistemas com finalidades científicas; d) pesquisas científicas cujo impacto sobre o ambiente seja maior do que aquele causado pela simples observação ou pela coleta controlada de componentes dos ecossistemas, em uma área correspondente a no máximo três por cento da extensão total da unidade e até o limite de 1.500 ha (um mil e quinhentos hectares).

Considerando o exposto a indicação de criação da ESECA, aponta-se como condição estratégica e diferencial a própria universidade, que possui cursos voltados a estudos ambientais, reabilitação de áreas degradadas, estudos de fauna e flora, hidrologia, solos, clima, recursos genéticos, produção de mudas de espécies nativas, uso de energias renováveis, entre outras. Dessa forma os pesquisadores teriam à disposição um vasto espaço geográfico para atuar nas, várias áreas do conhecimento de forma integrada, com a facilidade de acesso e monitoramento. $\mathrm{O}$ aporte logístico e de equipamentos existentes, sem a necessidade de custos voltados à criação de suporte físico e deslocamentos de equipes, para pesquisas de longo prazo em áreas distantes, seria de suma importância para acúmulo de conhecimento e divulgação de resultados, favoráveis ao manejo de UCs. Reforça-se ainda proposta criação da ESECA, o apoio que pode ser ofertado às questões de educação ambiental, devido à sua localização periurbana e a infraestrutura oferecida pela UNILAB (salas, auditórios, alimentação, banheiros, etc); distante apenas $60 \mathrm{Km}$ da capital cearense, poderia se tornar em pouco tempo, referência de educação ambiental em prazo curto. Acredita-se que com essas características, a ESECA também seria um polo de visitação por alunos de escolas de ensino fundamental e médio, estimulando a pesquisa e consciência ambiental de forma muito eficiente em toda região do maciço de Baturité e metropolitana do Ceará.

Como principal produto deste artigo fica apresentado o mapa da Figura 4, que é composto por três classes de área: edificado, expansão e ESEC. O mapa também vem acompanhado das áreas absolutas de percentuais do campus da Auroras da UNILAB. Fica então proposto uma Unidade de Conservação, domínio Estação Ecológica - ESEC de aproximadamente 95 ha, com a gestão exercida pela própria UNILAB. Esta ficaria 
responsável por indicar um gestor da UC; Criar uma Conselho Consultivo e Deliberativo (CCD); Estruturação equipe de funcionários e prestadores de serviço; Cercar todo o perímetro da UC; Definir o plano de manejo; Promover audiências públicas para coleta de sugestões, no sentido de promover melhorias a comunidade local; Desenvolver projetos de pesquisa, ensino e extensão na área de forma controlada, sistemática e integradas as demandas da UC; Estimular os confinantes a estabeleceram as áreas de reserva legal de suas propriedades nos limites com a ESECA, funcionando como zonas de amortecimento; Monitorar as condições ambientais e combater incêndios florestais com apoio do IBAMA e prefeituras municipais.

Ademais a universidade contribui ao compartilhar informações e ações com a gestão da APA no maciço de Baturité; estimular e apoiar a educação ambiental junto as prefeituras de Redenção e Acarape, bem como as demais prefeituras da região que solicitarem; estimular a recuperação de áreas degradadas na bacia do Rio Pacoti, focando no manejo de resíduos sólido, produção de água para mananciais e produção agropecuária integrada e de baixo carbono. A importância estratégica sociocultural, não somente para os discentes da Universidade, mas também, para a população que circunda a área, reforçam a proposta de criação de UC. Fazendo-se necessário desenvolver políticas de fomento e educação ambiental local como estratégias bastida de sua implantação. Tal proposta implica no dimensionamento de esforços e recursos distintos, assim como a geração e benefícios em médio e longo prazo.

A viabilidade da proposta seria potencializada com o apoio de iniciativa privada com interesse em ter compensações de pegadas ecológicas e patrocínio das pesquisas e manutenção da ESEC, que poderia valorar suas ações e fornecer certificados verdes. Outra fonte de recursos seriam as iminentes legislações que apontam o pagamento de serviços ecossistêmicos.

Figura 1. Mapa com área indicada para criação da ESEC Auroras, área em uso pela universidade e áreas indicadas para planos de expansão física, com tabela de indicação de áreas absolutas e relativas.

\begin{tabular}{ccc}
\hline \multicolumn{3}{c}{ indicadas para planos de expansão física, com tabela de indicação de áreas absolutas e relativas. } \\
Descrição & Áreas (ha) & $\begin{array}{c}\text { \% relativo à área do Campus } \\
\text { das Auroras }\end{array}$ \\
\hline Área ESECA & 94,50 & 71,17 \\
\hline Área Expansão Oeste & 7,68 & 3,90 \\
\hline Área Expansão Leste & 17,36 & 13,08 \\
\hline Área Edificada & 15,73 & 11,85 \\
\hline Área Auroras & 135,27 & 100,00 \\
\hline
\end{tabular}




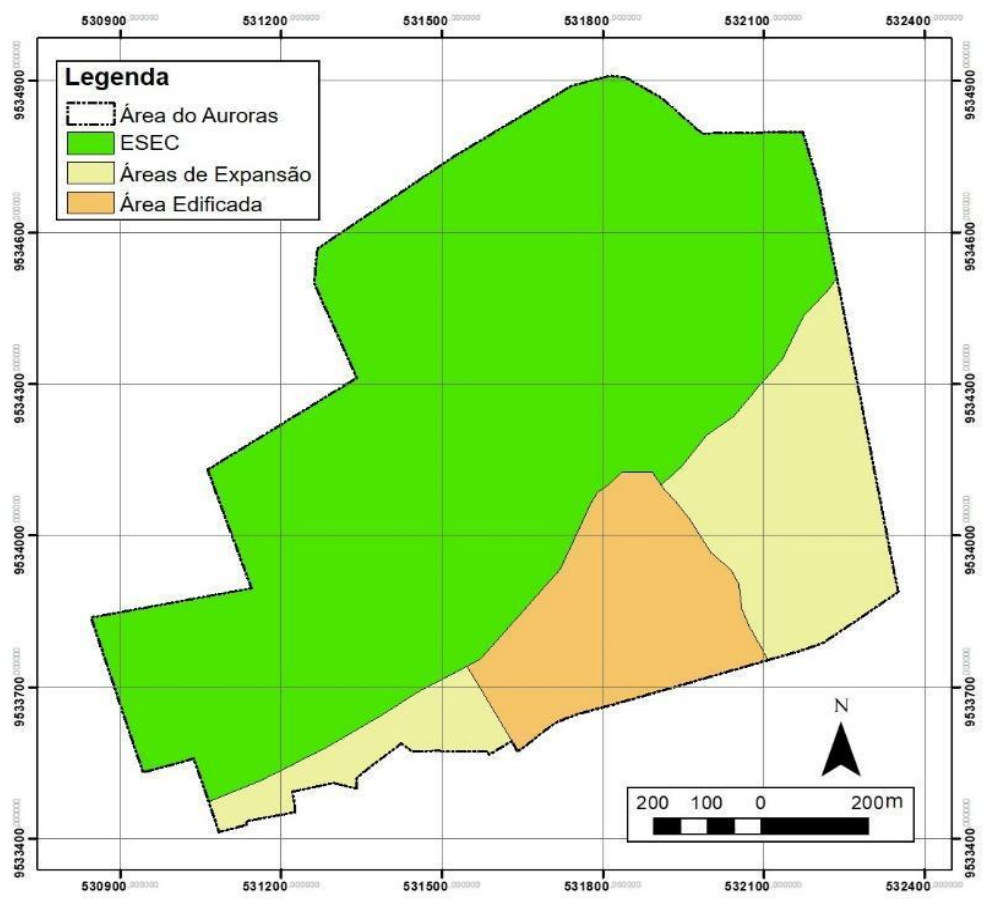

\section{CONCLUSÕES}

Foi realizado um estudo para propor a implantação de uma Unidade de Conservação do tipo Unidade de Conservação de Proteção Integral - Estação Ecológica Auroras (ESECA) no entorno do campus da Universidade da Integração Internacional da Lusofonia Afro-Brasileira (UNILAB). A proposta considera a relevância ambiental do perímetro da Universidade para justificar a necessidade de preservação da mata local.

A ESECA proporciona uma área de estudos relevante no contexto do semiárido cearense, em especial para realização de atividades de ensino, pesquisa e extensão para as escolas da região e para as universidades cearenses. Além de permitir e facilitar a realização de estudos integrados e de monitoramento relacionados aos cursos da UNILAB. Em relação aos custos, há a necessidade de designação de dotação orçamentária específica da Universidade, bem como a prospecção de outras fontes de fomento, a citar compensações ambientais (federais e estaduais) e fundos de direito difuso. Sugere-se a participação ativa da iniciativa privada para viabilizar a implantação desta UC.

\section{REFERÊNCIAS}

ANTUNES. P. B. Direito Ambiental. 8ª Ed. Rio de Janeiro: Lúmen Júris, 2005.

BEUCHLE, R.; GRECCHI, R. C.; SHIMABUKURO, Y. E.; SELIGER, R.; EVA, H. D.; SANO. E.; ACHARD, F. Land cover changes in the Brazilian Cerrado and Caatinga biomes from 1990 to 2010 based on a systematic remote sensing sampling approach. Applied Geography, v.58, Março 2015, p. 116-127 
BRASIL. Lei Complementar $n^{\circ}$ 140, de 8 de dezembro de 2011. Altera a Lei no 6.938, de 31 de agosto de 1981. Diário Oficial [da República Federativa do Brasil] de 9.12.2011 - e retificado em 12.12.2011, Brasília, DF.8p.

BRASIL. Lei n. ${ }^{\circ} 6.938$ de 31 de agosto de 1981. Política Nacional do Meio Ambiente PNMA, Brasília, DF, 1981.27p.

BRASIL. Lei $n^{\circ}$ 9.985, de 18 de julho de 2000; Decreto $n^{\circ} 4.340$, de 22 de agosto de 2002.Sistema Nacional de Unidade de Conservação da Natureza - SNUC: 3. ed. aum. Brasília: MMA/SBF, 2003.52p.

BRASIL. Ministério do Meio Ambiente. Unidades de Conservação. Criação de UC. Disponível em: <http://www.mma.gov.br/areas-protegidas/unidades-de-conservacao/criacaoucs>. Acesso em: 20/01/2018.

BRASIL. Lei no 12.651, de 25 de maio de 2012. Novo Código Florestal Brasileiro. Brasília, DF, 2012.35p.

DOS SANTOS, R. M.; VIEIRA, F.A. Similaridade florística entre formações de Mata Seca e Mata de Galeria no Parque Municipal da Sapucaia, Montes Claros-MG. Revista Científica Eletrônica De Engenharia Florestal - ISSN 1678-3867 Ano IV, n.07, 2006. 10p.

FERNANDES, A. Biodiversidade da caatinga. In: Biodiversidade, conservação e uso sustentável da flora do Brasil. Recife: UFRPE, 2002.

LEITE, R. A.; SANTOS, M. T. L. F. Incongruências na criação de unidades de conservação: um Estado de Caso da "Flora de Açu". Revista do Direito Público, Londrina, v.10, n.3, 2015.141-154p.

LEMOS, J. R., \& Meguro, M. (2015). Estudo fitossociológico de uma área de Caatinga na Estação Ecológica (ESEC) de Aiuaba, Ceará, Brasil. Revista Biotemas, v.28(2), 39-50p.

MACHADO, R. B.; RAMOS NETO, M. B.; PEREIRA, P. G. P.; CALDAS, E. F.; GONÇALVES, D. A.; SANTOS, N. S.; TABOR, K.; STEININGER, M. Estimativas de perda da área do Cerrado brasileiro. Relatório técnico não publicado. Conservação Internacional, Brasília, DF, 2004.10p.

MARINHO, F. P.; MAZZOCHINI, G. G.; MANHÃES, A. P.; WEISSER, W. W.; GANADE, G. Effects of past and present land use on vegetation cover and regeneration in a tropical dryland forest. Journal of Arid Environments, 132, 2006.26-33p.

MCKINNEY, M.L., Urbanization, biodiversity, and conservation. BioScience, v. 52, 2002. 883-890p.

MEDA. R. V. A criação de Unidades de Conservação no reconhecimento de territórios às populações tradicionais. Revista de Direito da Cidade, v.06, n01. 2014.275-300p.

MORO, M. F.; CASTRO, A. S. F.; ARAÚJO, F. S. Composição Florística e estrutura de um fragmento de vegetação savânica sobre os tabuleiros pré-litorâneos na zona urbana de 
Fortaleza, Ceará. Rodriguésia - Revista do Jardim Botânico do Rio de Janeiro, v. 62 n. 2, 2011. 407-423p.

OLIVEIRA, G. F.; GARCIA, A. C. L.; MONTES, M. A.; JUCÁ, J. C. L. D. A.; VALENTE, V. L. D. S.;ROHDE, C. Are conservation units in the Caatinga biome, Brazil, efficient in the protection of biodiversity? An analysis based on the drosophilid fauna. Journal for Nature Conservation, v.34, 2016.145-150p.

UNDP, UNEP, WB, WRI - United Nations Development Program, United Nations Environment Program, World Bank, World Resources Institute. 2000. World resources 20002001: people and ecosystems: the fraying web of life. Elsevier, Amsterdam. 389p. 